Each chapter explores medical, legal, ethical and religious beliefs, tackling issues of: forgoing treatment versus suicide; withholding versus withdrawing treatment; terminal illness; beyond the persistent vegetative state; severe dementia, and artificial nutrition and hydration.

The author has used various case studies and opinion polls to argue various points and to highlight ethical dilemmas faced by health care professionals. The book includes recommendations from various groups, including the American Medical Association, the American Nurses Association, the Catholic Health Association, and The President's Commission.

To clarify the findings the author has used tables and boxes: box 1, page 8 , describes the persistent vegetative state. Table 1.1 , page 9 , looks at the persistent vegetative state and syndromes often confused with this. Table 3.2 , page 72 , explores attitudes about refusing life-sustaining treatment for oneself. Table 3.3, page 73, explores choices regarding the use of lifesustaining treatment if in a persistent vegetative state. Table 3.6 , page 83 , deals with attitudes versus behaviour regarding advance directives. Table 3.7 , page 86 , focuses on institutional objections to withholding and withdrawing treatments in hospitals, and table 3.8 , page 87 , looks at institutional objections to withholding and withdrawing treatments in nursing homes.

Good examples are given throughout the book to help explain what medical procedures are available and the advantages and disadvantages of their use. There is a full explanation of the methods by which artificial nutrition is given and the positive and negative aspects of the various procedures.

This would be a very good basic reference book for all health care professionals, clarifying as it does, certain concerns the primary health care team may have when considering the right path to follow, when meeting the needs of the dying patient.

Although it is promoted as a first guide to the patient, family members and care providers I am not sure if it would be too distressing for the patient to read, because of the complexity of the subject and the differing opinions held by so many health care professionals. Practices and policies vary too much at present, depending on where you are treated and by whom.
Since the book concentrates on the USA and uses its legal structure and procedures, I do not feel it would apply to the United Kingdom in the same way. Therefore, for the patient and his/her family in the UK the book is open to misinterpretation and could lead to misunderstanding.

The considerable power of the courts is described at the beginning of the book, in a case study. It is clear that the court decided in what it considered was in the patient's best interests, and it has to be accepted that if the relative's wishes are overridden by the court, yet another dimension of stress and anxiety is added to what the family has to bear, at a time when they are already emotionally vulnerable.

Finally, I dislike the cover and title of the book. The black/red lettering and the blue/yellow colours are cold and hard. White and pastels are warmer and gentler when dealing with the subject of death and dying.

JACQUELINE T HARDY Senior Palliative Care Sister, Macmillan Unit, Bournemouth and Christchurch Hospitals NHS Trust

\section{Ethical decision making in therapy practice}

\section{Julius Sims, Oxford, Butterworth- Heinemann, 1997, 177 pages, $£ 16.99$.}

This book is the first in the UK to address ethical issues in the therapy professions. It is aimed at practising therapists and students and is both readable and stimulating. The focus of the book is on the ethics of clinical practice and it does not attempt to address the equally important ethical issues around research and therapy. The book covers a range of subjects in chapters on: Introduction to ethics; Ethical decision making; Truthfulness; Informed consent; Confidentiality; Death and dying; Resource allocation, and Codes of ethics and in less depth Advocacy; Suicide; Care of older people, and HIV infection. Each chapter has a summary that serves as a reminder of the key points in the chapter.

The first chapter, Introduction to ethics, is refreshingly simple, with a very clear explanation of the subject, in particular in its description of ethics and why this is an important issue for therapists to address. The author is not afraid to tackle difficult concepts such as the relationship between morality and ethics and law and ethics.

The book continues to hold the attention and provoke interesting discussion, for example in the chapter on Death and dying. The author states that this may "not impinge significantly on professional practice in the therapies". However, it is important that therapists have a knowledge and interest in other areas of health care that impact on their colleagues in the multi-professional team.

The issues surrounding resource allocation appeared to give the author the most difficulty and there was a strong feeling of underlying anxiety and anger. He points out that therapists ignore such issues at "their professional peril". The chapter attempts to answer the question of how therapists can ensure that resource allocation decisions are made appropriately. He cites three main considerations for resource allocation: efficiency, effectiveness and equity (the three Es). He makes an excellent attempt to clarify this issue and provides the reader with both a taster on the subject and a sound base from which to enlarge on this particular area.

The author shows no bias towards any one therapy and the contents are as relevant for a physiotherapist, as for a speech and language therapist or for an occupational therapist, which is an indication of the quality of the writing and the content.

While being both readable and stimulating the book also contains some clear definitions which would be useful to the practising therapist. It provides an excellent starting point for therapists and for the multiprofessional team considering these complex issues. As the author points out in the book it is important for all those in the business of health care to understand ethical issues "beyond the confines of their own professional activities".

The book should be included in the recommended reading list of multiprofessional undergraduate training courses as well as available for all practising therapists. Julius Sims has addressed complex subjects with clarity and given therapists a useful tool. This book is long overdue and should encourage greater discussion amongst therapists.

LYNCH MASON, DIPCOT SROT Occupational Therapist 